\title{
The content and specifics of professionally important qualities of nurses
}

\author{
M. V. Ekaterinina ${ }^{1}$, E. V. Karpova ${ }^{2}$
}

${ }^{1}$ Yaroslavl Medical College, 10/16 Gagarina str., Yaroslavl 150023, Russian Federation

${ }^{2}$ K. D. Ushinsky Yaroslavl State Pedagogikal University, 108/1 Republican str., Yaroslavl 150000, Russian Federation

DOI: $10.18255 / 1996-5648-2021-4-610-623$

Research article Full text in Russian

The article presents the results of theoretical analysis and empirical studies of the problem of determining and explaining the complex of professionally important qualities of one socially significant type of activity - the activity of nurses. Based on the principle of complementary analysis of literary data and materials of the author's research, the main professionally im-portant qualities of a nurse are identified and characterized, the main of which are attentional abilities in general and switchability, and concentration of attention, in particular; communicative and organizational abilities; empathy, self-control, as well as internality, which is the basis of an even more generalized qualityresponsibility. These qualities are interpreted on the basis of the synthesis of personnel profile analysis approach and competence approaches. Special attention is paid to the logic and history of the development of ideas on this problem, as well as the explication of the dif-ficulties and unresolved problems that it has led to at the present time and possible ways to minimize them.

Keywords: professionally important qualities; nurse; students; subject of activity; pro-fessionogenesis; competence approach; personnel profile analysis approach

\section{INFORMATION ABOUT AUTHORS}

\author{
Karpova, Elena V. | E-mail: evkar55@yandex.ru \\ Doc. Sc. (Psychology), Professor
}

\begin{tabular}{l|l} 
Ekaterinina, Maria V. & $\begin{array}{l}\text { E-mail: ekaterinina.m@yandex.ru } \\
\text { Master of psychology, teacher }\end{array}$
\end{tabular} 


\title{
Содержание и специфика профессионально важных качеств медицинских сестер
}

\author{
М. В. Екатеринина ${ }^{1}$, Е. В. Карпова ${ }^{2}$
}

\begin{tabular}{l}
${ }_{1}^{1}$ Ярославский медицинский колледж, ул. Гагарина, д. 10/16, Ярославль, 150023, Российская \\
Федерация \\
${ }^{2}$ Ярославский государственный педагогический университет им. К. Д. Ушинского, \\
ул. Республиканская, 108/1, Ярославль, 150000, Российская Федерация \\
\hline
\end{tabular} DOI: 10.18255/1996-5648-2021-4-610-623 УДК 159.9

Научная статья Полный текст на русском языке

Представлены результаты теоретического анализа и эмпирических исследований проблемы определения и объяснения комплекса профессионально важных качеств одного социально значимых видов деятельности - деятельности медицинских сестер. На основе принципа взаимно дополнительного анализа литературных данных и материалов авторского исследования определены и охарактеризованы основные профессионально важные качества медицинской сестры, главными из которых являются аттенционные способности в целом и переключаемость и концентрация внимания в частности; коммуникативные и организаторские способности; эмпатия, самоконтроль, а также интернальность, лежащая в основе еще более обобщенного качества - ответственности. Эти качества проинтерпретированы с позиций синтеза профессиографического и компетентностного подходов.

Ключевые слова: профессионально важные качества; медицинская сестра; студенты; субъект деятельности; профессиогенез; компетентностный подход; профессиографический подход

\section{ИНФОРМАЦИЯ ОБ АВТОРАХ}

Карпова, Елена Викторовна

Екатеринина, Мария Валентиновна
E-mail: evkar55@yandex.ru

Доктор психологических наук, профессор

E-mail: ekaterinina.m@yandex.ru

Магистр психологии, преподаватель

\section{Постановка проблемы}

Профессия медицинской сестры является одной из весьма важных прежде всего в практическом отношении, поскольку от нее в значительной степени зависит обеспечение должного уровня медицинского обслужива(C) Екатеринина М. В., Карпова Е. В., 2021

Статья открытого доступа под лицензией СС ВY (https://creativecommons.org/licenses/by/4.0/) 
Жедунова Л. Г., Посысоев Н. Н.

ния и в конечном итоге - здоровья людей. В свою очередь, успешность этой деятельности во многом определяется наличием личностных и профессиональных качеств, необходимых с точки зрения содержания и условий данной деятельности, равно как и требований, предъявляемых к нормативному уровню ее реализации. Необходима дифференциация и последующее осмысление тех профессионально важных качеств, которые релевантны этой деятельности, а также определение их специфики по отношению к другим видам медицинской деятельности.

Данная проблема разрабатывается в настоящее время не только в классической парадигме, базирующейся на понятии ПВК, но и в парадигме компетентностного подхода. При этом наряду с достоинствами данного подхода систематически подчеркиваются и его ограничения [1-2], главным из которых, по мнению Ter Maten-Speksnijder и др., является трудность интеграции компетенций в реальных ситуациях [см. по: 2, с. 63]. Chaiklina и Sievert считают, что «ориентация только на компетентность не может обеспечить студентов адекватными концептуальными инструментами для интерпретации и компетентного поведения в практических ситуациях» [см. по: 2, с. 58], и приводят результаты исследования Ter MatenSpeksnijder и др. (2015), в котором выявилась сильная тенденция у студентов фокусироваться на лечебных аспектах (то есть на состоянии здоровья), в то время как психосоциальные аспекты (например, пожелания пациента) часто игнорировались [см. по: 2 , с. 63].

Комплексное изучение и описание содержательных и структурных характеристик ПВК медицинских сестер, также как и базовых компетенций данной деятельности, должно базироваться на реализации методологии профессиографирования. Так, в частности, в этой связи Нојаt отмечает, что сегодня не существует единого мнения даже о количестве и характере личных качеств, необходимых для профессионализма в медицине [3, с. 174]. Это мнение является очень показательным, поскольку и другие авторы также придерживаются сходной точки зрения. В связи с этим становится очевидной необходимость специального рассмотрения вопроса о дифференциации - определении и интерпретации состава и содержания ПВК медицинских сестер.

Сорормулированная выше цель может быть конкретизирована до задачи разработки психограммы медицинской сестры, то есть важнейшего раздела профессиограммы, который и содержит перечень ПВК. Данная задача решалась нами на основе сочетания профессиографического и компетентностного подходов, поскольку их интеграция является важным условием обеспечения полноты психограммы в целом.

\section{Профессиографический анализ деятельности медицинских сестер}

В проведенном нами эмпирическом исследовании приняли участие студенты 1-3 курсов Ярославского медицинского колледжа, состав по полу 
Содержание и специфика профессионально важных качеств...

однороден - женский. Для обработки результатов использовалась программа «IBM SPSS Statistics 23».

Первое профессионально важное качество - это концентрация и переключаемость внимания. Действительно, в силу специфрики своей профессиональной деятельности медицинская сестра проводит с пациентами больше времени, чем врач, поэтому эфрфективность деятельности во многом обеспечивается развитием у нее избирательной направленности внимания на осуществление сестринского ухода. Следует рассматривать внимание медсестры как социальное, иначе говоря, субъект-субъектное [4]; данный тип внимания предполагает постоянные межличностные контакты, предопределяя тем самым выработку “специализированного» профессионального внимания [4, с. 93]. У студентов медицинского колледжа деятельностная специфика будущей профессии закладывается фрактически с первого курса обучения: уже в начале учебного года студенты проходят производственную (в медицинском учреждении) и учебную (в колледже) практики. В нашем исследовании, проведенном с использованием методики корректурной пробы [5, с. 25], было выявлено, что на 1-м курсе обучения высокий и очень высокий уровень развития концентрации внимания - у 68 \% опрошенных, на 2-м - у 52 \% и на 3-м - у 52 \%. Существенно повышение количества опрошенных, имеющих средний уровень свойств внимания. Так, на 1-м курсе средний уровень развития концентрации внимания выявлен у $20 \%$ студентов, на 2-м - у $32 \%$, на 3-м - у $40 \%$. Высокий и очень высокий уровень развития переключаемости внимания на 1 курсе - у 84 \% респондентов, на 2-м - у $76 \%$, на $3-\mathrm{m}$ - у $92 \%$.

Высокий уровень развития переключаемости внимания у студентов зависит также и от внешних условий. Необходимо обратить внимание на параметры эффрективности любой профессиональной деятельности, к которым В. Д. Шадриков относит производительность, качество и надежность деятельности [6, с. 27]. Сама организация профессиональной деятельности медсестры предполагает ежедневный контакт с большим количеством пациентов, которым необходимо быстро и качественно предоставлять медицинские услуги, и поэтому особенности среды профессионального образовательного учреждения для обучающихся по специальности «Сестринское дело» для проявления креативности ограничены. Согласно мнению В. Д. Шадрикова, параметр производительности в инженерно-психологических работах трансорормируется в параметр скорости выполнения тех или иных действий [6, с. 27], а значит, необходимой для осуществления медицинских услуг мерой производительности для медицинской сестры будет скорость выполнения медицинских манипуляций. Например, в ГОСТе Р 52623.3-2015 «Технологии выполнения простых медицинских услуг. Манипуляции сестринского ухода» указаны коэффициенты условных единиц трудоемкости для медсестры [7]. Условные единицы трудоемкости определены в «Инструкции по расчету стоимости медицинских услуг» [8], 
Жедунова Л. Г., Посысоев Н. Н.

в которой указывается, что «трудоемкость измеряется затратами времени на оказание медицинской услуги». В целях упрощения расчетов целесообразно трудоемкость измерять в условных единицах трудоемкости (УЕТ), приняв время, равное 10 минутам, за 1 УЕТ [8]. Так, например, по ГОСТу «Технологии выполнения простых медицинских услуг. Манипуляции сестринского ухода» постановка горчичников соответствует коэфорициенту УЕТ медицинской сестры - 1,5 (15 минут), а постановка пиявок - 3 (30 минут) [7]. Данные временные интервалы могут не соответствовать реальной обстановке, в которой будут находиться медсестра и пациент, но время выполнения данных медицинских манипуляций не может превышаться или занижаться в значительной степени от допустимых норм. Высокая рабочая нагрузка и ответственность при большом потоке пациентов способствует развитию «наиболее полезного» качества для медсестры - переключаемости внимания.

В исследованиях установлено, что $20 \%$ медсестер совершают хотя бы одну ошибку во время своего рабочего времени [см. по: 9, с. 1]. В работе Mohsenpour и др. была выявлена частота самых распространённых причин ошибок студентов-медсестер отделения неотложной помощи, это прежде всего окружающие шумы (2-е место по частоте), невнимательность (6-е место), невнимание к дозировке лекарства в карточке лекарства (18-е место) [9, с. 5]. Вышеперечисленные фракты приводят к закономерному выводу: концентрация и переключаемость внимания - это необходимые ПВК в работе медсестры.

Второе основное ПВК - это коммуникативнъе способности. Необходимость коммуникативных навыков в работе медсестры подчеркивается многими авторами. Эффективные коммуникативные навыки, как отмечают Sharifabad Morowati и др., являются неотъемлемой частью профессии медсестры и одним из важных инструментов поддержки пациентов и их родственников [10, с. 164]. Исследования некоторых авторов (Karimi и др., 2013; Taghizadeh и др., 2018) продемонстрировали, что повышение коммуникативных навыков медсестер привело к повышению качества медицинской помощи [11].

В нашем исследовании был выявлен низкий уровень развития коммуникативных способностей у студентов. На 1-м курсе обучения уровень коммуникативных способностей высокий и очень высокий у $24 \%$ респондентов, на $2-\mathrm{m}$ - у $16 \%$, а на 3-м - у $12 \%$ (ниже среднего и низкий уровень у $90 \%$ выпускников).

Обратим внимание, что в Федеральном государственном образовательном стандарте среднего профессионального образования по специальности 34.02.01 «Сестринское дело» (базовая подготовка) даны требования к результатам освоения программы подготовки специалистов среднего звена в виде общих и профессиональных компетенций, в содержании которых 
Содержание и специфика профессионально важных качеств...

определены коммуникативные компетенции (ОК 6, ПК 2.1, ПК 2.3, ПК 3.3) [12].

По мнению Y. ten Hoeve, на профрессиональное становление студентов-медсестер негативно влияет большой «теоретико-практический разрыв»: на практике медсестры сталкиваются с неопределённостью, тревогой, стрессом из-за высоких требований к навыкам и умениям. Она выявила, что в лонгитюдной группе (n = 123) почти четверть студентов-медсестер рассматривали возможность уйти из образовательной программы и одной из причин этого желания студенты указывали на несоразмерные доли теории, которая преобладает над практикой [13, с. 80].

Следующее очень значимое ПВК, дифференцируемое как по материалам зарубежных исследований, так и нашим данным, - это организаторские способности. Качество медицинских услуг, предоставляемых медсестрой, также зависит от уровня развития организаторских способностей, сущность и содержание которых в общем плане наиболее полно раскрыто Л. И. Уманским. Он выделяет следующие основные организаторские качества: психологическую избирательность, практический психологический ум, психологический такт, общественную энергичность, требовательность, критичность, склонность к организаторской деятельности [см. по: 14, с. 44]. Общеорганизаторские способности дополняются и конкретизируются более локальными способностями, которые обусловливают эфрективное выполнение отдельных управленческих фрункций. Основными из них, по классифрикации А. В. Карпова, являются способности к целеполаганию, прогнозированию, планированию, принятию управленческих решений, а также коммуникативные способности, мотивирующие способности и способности контроля [см. по: 14, с. 44-45]. Для медсестры данные локальные организаторские способности в большей степени раскрываются в процессе клинического принятия решений. Некоторыми авторами (Banning, 2008; Florin, Ehrenberg, Ehnfors, 2008) клиническое принятие решений определяется как «мыслительный процесс выбора альтернатив при оказании помощи пациентам, включающий как диагностические рассуждения, так и клинические суждения» [см. по: 15, с. 52]. Другие исследователи (Cranley, Doran, Tourangeau, Kushniruk, Nagle, 2009) считают, что в процессе принятия клинических решений «медсестры должны точно оценивать и выявлять отклонения от нормальной клинической картины здоровья или болезни и принимать решение на основе представленных данных» [см. по: 15, с. 52]. По мнению Benner, опыт имеет первостепенное значение для процесса клинического принятия решения, a Stinson отмечает, что в условиях интенсивной терапии «решения принимаются часто и быстро и задержка в процессе принятия решений может быть вопросом жизни и смерти» [15, с. 52]. Поэтому особую важность представляет рассмотрение динамики развития организаторских способностей у студентов-медсестер. 
Жедунова Л. Г., Посысоев Н. Н.

Исследование Jahanpour и др., проведенное на студентах-медсестрах выпускного курса, (n = 32), показало, что они, как правило, не могли самостоятельно принимать клинические решения [16]. Аналогичные результаты были получены в исследовании Dicle и Edeer Durmaz: оценки восприятия принятия клинических решений перед выпуском у студентов были низкими по сравнению с другими курсами обучения. Предпринимая попытку объяснения этих данных, авторы отмечают, что «восприятие принятия клинических решений у младших улучшается по мере того, как они развивают навыки самостоятельного ведения 2-3 пациентов в клинике, а старшие оценивают свое восприятие принятия решений ниже из-за увеличения их требований перед лицом различных клинических случаев, встречающихся в практике интернатуры» [17, с. 143].

В нашем исследовании на 1-м курсе обучения уровень организаторских способностей у студентов оказался высоким и очень высоким у $24 \%$ респондентов, на 2-м - у $40 \%$, а на 3-м - у 32 \% (ниже среднего и низкий уровень - у 56 \% выпускников). Низкий уровень развития организаторских способностей зависит от объективных требований будущей профессиональной деятельности, так называемых "внешних критериев дифференциации ПВК» [18, с. 174]. Внешними критериями диффреренциации ПВК для медсестер могут служить полнота и точность выполнения распоряжений врачей относительно проведения лечения пациентов. Так, например, Elham и др. в исследовании по изучению удовлетворенности пациентов качеством сестринского ухода обнаружили, что медсестры имели более высокий балл в измерении «следование правилам» и более низкий в измерении «автономия» [19].

В роли еще одного ПВК в деятельности медицинской сестры выступает эмпатия. Williams и Stickley замечают: «Хотя эмпатия широко признана и, как ожидается, будет центральным компонентом отношений медсестры и пациента, восприятие пациента заключается в том, что она часто отсутствует» [20, с. 755]. Batson указывает, что при наличии соответствующих фоновых условий эмпатия имеет тенденцию приводить к симпатии и, как следствие, к альтруистической мотивации [см. по: 21, с. 9], а значит, развитие эмпатии напрямую зависит от развития мотивации заботиться о других. В. Д. Шадриков, описывая личностные качества (заботливый, совестливый, мужественный и т. д.), показывает, что за каждым из них стоит развитая, приобретенная или трансформированная мотивация: «..Формируются и воспитываются не качества личности, а мотивации субъекта» [22, с. 194]. Умение сопереживать зависит от желания помочь пациенту справиться с болью, успокоить его и дать психологический настрой на управление болью, но данное умение требует от медсестры сил и времени.

В нашем исследовании высокий уровень эмпатии имеется лишь у малой части опрошенных. Так, на 1-м курсе - у $12 \%$ студентов, на 2-м - у $16 \%$ и на $3-\mathrm{M}$ - также у 16 \% (при этом низкий уровень на 1-м курсе был особенно 
высок - у 56 \% респондентов, на 2-м-у $20 \%$, а на 3-м - у 24 \%). Результаты нашего исследования согласуются с рядом других исследований. Wilson обратил внимание на изменение характера эмпатии в зависимости от периода обучения: «...Студенты первого курса сестринского дела показали большую эмпатию по сравнению со студентами последнего курса» [см. по: 23, с. 80]. В исследовании Sedaghati Kesbakhi и Rohani $(\mathrm{n}=122)$ обнаружено, что уровень эмпатии значительно снижается у студентов-медсестер на четвертом году обучения по сравнению с первым годом [24]. Ward и др. назвали ореномен снижения эмпатии у студентов на третьем курсе «загадкой эмпатии» [25, с. 37], так как предполагается, что эмпатия должна возрастать. Однако данное явление было обнаружено и в других исследованиях (Bellini, Shea, 2005; Benbassat, Baumal, 2004; Hojat и др., 2009) [см. по: 25, с. 37]. Coulmas (2006) обнаружил, что на выражение сочувствия медсестер к своим пациентам в клинических условиях влияет не сам стаж работы, а накопленное влияние временных ограничений на взаимодействие медсестры и пациента [см. по: 25, с. 37]. Умение сопереживать зависит от количества времени, уделяемому медсестрой пациенту и его семье [26, с. 10].

Профрессиональная деятельность медсестры носит субъект-субъектный характер, но результативные параметры деятельности (точность, производительность, эффрективность, надежность) трансформируют ее в субъект-объектную деятельность, что наиболее полно отражается в понятии, используемом в зарубежной литературе как «функциональный уход», при котором пациенты «машинально обрабатываются» без личного и эмоционального контакта [27, с. 79]. В исследовании Büssing приводятся слова одного из медицинских работников: «Сборочная работа на человеке. Больше об этом, собственно, и говорить нечего. Точно так же, как я могу закрутить десять колесных гаек на десяти автомобилях, я, конечно, могу измерить артериальное давление на двенадцати пациентах, поставить ингалятор, заправить кровати, как машина» [см. по: 27, с. 79]. Данное высказывание подтверждается нашими результатами исследования: у студентов к концу освоения образовательных программ особо развиты концентрация и переключаемость внимания в противовес менее развитым, но описываемым исследователями как «необходимые»- эмпатия и коммуникативные качества. Кроме профессии медицинской сестры, снижение эмпатии доказано и в других социономических профессиях. Например, в работе [28] показано, что эмпатия у учителей начальных классов вместе со стажем работы снижается, что, в свою очередь, показывает расхождения парадигмы ПВК-подхода, отмечаемые В. А. Толочеком [1], с реальным формированием ПВК для целого ряда профрессий.

Безусловно, деятельность медсестры не может быть успешной без такого качества, каковым выступает самоконтроль. Еуімауа и др. замечают, что «...сестринское дело - это профессия, требующая быстрых и важных решений, медсестры должны рассмотреть несколько вариантов одновремен- 
Жедунова Л. Г., Посысоев Н. Н.

но и быстро принять решение. Поэтому они должны обладать высоким уровнем самоконтроля» [29, с. 1013]. Garnefski, Kraaij и Spinhoven считают, что самоконтроль выступает психологическим механизмом совладания со стрессом [см. по: 29, с. 1013]. Barrick и Mount указывают на взаимосвязь между трудовыми результатами и «Большой пятеркой личностных черт», и поэтому самоконтроль считается определяющим фрактором профессиональной деятельности для всех профессий [см. по: 29, с. 1014].

Smith (2011) подчеркивает, что для некоторых пациентов чувство, что медсестры испытывают к ним эмоции, может восприниматься как угроза; пациент должен чувствовать, что уход безопасен, и это требует, чтобы медсестры управляли эмоциями таким образом, который может отличаться от их естественных «заботливых» качеств [см. по: 30, с. 17].

Эмпирическое исследование Еуімауа и др. по самоконтролю студентов-медсестер ( $\mathrm{n}=488)$ показало низкие уровни самоконтроля по шкалам опытного самоконтроля, ревизионного и восстановительного. Опытный самоконтроль (experiential self-control) происходит автоматически и бессознательно; чтобы уравновесить фризиологические фрункции индивида, он мотивирует индивида быть открытым для новых впечатлений и приятных занятий, таких как прослушивание музыки или поход в кино. Ревизионный самоконтроль (revisionary self-control) не является автоматическим; он сознателен и помогает защититься от разрушительных привычек и приспособиться к новым ситуациям, это также и воля к актуализации сложных форм поведения и привычек, таких как начало диеты, экономия денег, отказ от сигарет и т. д. Восстановительный самоконтроль (restorative self-control) также не автоматический, а сознательно восстанавливающий; он состоит из управляемого поведения, влияющего на эмоции, боль и когнитивные способности человека, и это поведение реорганизует неудачи и помогает сбалансировать жизнь человека [29, с. 1015-1016]. Самым низким видом самоконтроля был опытный самоконтроль, а самым высоким - ревизионный. Причиной этого, по мнению авторов, может служить интенсивное теоретическое и практическое обучение и сложные условия работы медсестер. Медсёстрам необходимо уметь преодолевать трудные ситуации [29, с. 1015-1016].

В нашем исследовании повышенный и высокий уровень эмоционального самоконтроля на 1-м курсе был выявлен у 56 \% опрошенных, на 2-м - у 40 \%, на $3-\mathrm{м}$ - у 44 \%. Повышенный и высокий уровень самоконтроля в деятельности студентов на 1-м курсе был выявлен у 52 \% опрошенных, на 2-м - у 80 \%, на $3-\mathrm{M}-$ у 68 \%. Повышенный и высокий уровень социального самоконтроля на 1-м курсе был отмечен у 40 \% опрошенных, на 2-м -у 68 \%, на 3-м - у $56 \%$. Наблюдается снижение эмоционального самоконтроля у студентов к выпускному курсу, по сравнению с 1 курсом,(к чему относится?) остальные шкалы показали постепенное развитие, и самым высоким показателем самоконтроля для выпускного курса стал самоконтроль в деятельности. 
Содержание и специфика профессионально важных качеств...

И, наконец, необходимо дифференцировать еще одно ПВК - ответственностъ. Ответственность как атрибуция у студентов-медсестер в нашем исследовании измерялась при помощи методики измерения локуса контроля «Тест-опросник субъективного контроля (УСК) Дж. Роттера» (адаптирован Е. Ф. Бажиным, С. А. Голыкиной, А. М. Эткиндом) [31]. Интерпретация результатов производилась согласно установленным авторами методики границам шкалы интернальности; было определено, что интернальный локус контроля наблюдается у большинства студентов. На 1-м курсе интернальный локус контроля - у 64 \% студентов, на 2-м у $80 \%$, а на $3-\mathrm{m}$ - у $72 \%$. Кроме этого, были определены уровни интернальности по всем группам опрошенных и преимущественно выявлен средний уровень интернальности: на 1-м курсе - у $92 \%$ респондентов, на 2 -м - у $96 \%$, на $3-\mathrm{m}$ - у $100 \%$. Средним уровнем интернальности обладает большинство людей, но решающим в поведении будет конкретная социальная ситуация [31]. Интернальный локус контроля для медсестер наиболее предпочтителен. При экстернальном локусе контроля медсестра возлагает ответственность за результаты медицинских манипуляций на внешние факторы: судьбу, случайность или других людей.

Обнаружена положительная корреляция между ответственностью и концентрацией. Эти переменные имеют сходную, идентичную причину динамики изменений, то есть чем более ответственны медсестры, тем они более сконцентрированы на качественном выполнении своих трудовых обязанностей, и наоборот. Так, например, Amini, Rahimi, Salehi и др., а также Hudson указывают, что ответственные медсестры концентрируются на своих задачах и заданиях и полностью выполняют их [см. по: 32, с. 8]. Отрицательная корреляция между ответственностью и переключаемостью внимания поднимает другой вопрос - о возможности наличия причинно-обусловленной связи между данными переменными. Причиной этой связи, по нашему мнению, может выступать прокрастинация как фактор повышения уровня развития переключаемости внимания и снижения уровня развития ответственности у медсестер. Прокрастинацию мы рассматриваем как противоположное личностному качеству «ответственность», что, в свою очередь, как утверждает Ferrari, «такое поведение вполне может рассматриваться как способ избежать ответственности» [см. по: 33, с. 28]. Согласно Khoshouei, одним из факторов, приводящих к прокрастинации, являются особенности работы [34, с. 28]. Некоторые ученые (Wood, Saylor, Cohen; Sagone, De Caroli; Engin, Zeliha, Didem; Abbasi, Pirani, Dargahi, Aghavirdi Nejad) считают, что «локус контроля - это индивидуальный фактор, влияющий на прокрастинацию» [см. по: 34, с. 28]. Khoshouei рассматривает взаимосвязь прокрастинации, особенностей работы и локуса контроля по результатам исследования среди 193 медсестер. В исследовании обнаружилась положительная сильная связь между прокрастинацией и внешним локусом контроля $(\mathrm{r}=0,24, \mathrm{p}<0,01)$ [24]. Как пишет Khoshouei, 
Жедунова Л. Г., Посысоев Н. Н.

«тяжелые работы и постоянно сменяющиеся смены в сестринской профессии могут быть причиной прокрастинации среди медсестер» [34, с. 32]. Для медсестры важным является придерживаться правильного использования времени и своевременного выполнения дел, т. к. промедление или неоправданная задержка может привести к неблагоприятным последствиям, но сменяющиеся условия работы способствуют развитию переключаемости внимания и вместе с тем изменению ответственности.

Нами сделан вывод об ответственности как наиболее необходимом ПВК в работе медсестры. Планирование и проведение ухода за пациентами, терапевтическое общение, обеспечение питания, гигиены, мобилизации (изменение положения неподвижного пациента), инфекционного контроля и введения лекарств, а также документация являются основными видами деятельности медсестер. Все это напрямую зависят от личной ответственности медсестер.

\section{Заключение}

Несмотря на очевидную практическую и теоретическую значимость исследования профессиональной деятельности медицинских сестер, она до сих пор остается явно недостаточно изученной. В особой степени это относится к вопросу о дифференциации и интерпретации ПВК данной деятельности, выступающих ее базовыми субъектными детерминантами, в решающей степени влияющими на ее эфрективность. $\mathfrak{K}$ настоящему времени сложились два основных подхода к разработке данной проблемы - подход, основанный на понятии ПВК, и компетентностный подход. Проведенный анализ показывает, что их недопустимо абсолютизировать и тем более противопоставлять. Наоборот, они должны быть поняты как комплементарные, раскрывающие разные аспекты единой по содержанию проблемы. Синтетическое использование этих подходов позволило выявить и охарактеризовать совокупность наиболее значимых ПВК медицинских сестер. При этом был использован метод сопоставительного анализа литературных данных и результатов собственных эмпирических исследований.

Определение наиболее значимых ПВК медицинских сестер, точнее, их перечня, с одной стороны, ставит логически следующие в познавательном отношении вопросы: каковы закономерности их организации в целом и структурирования в особенности? каковы закономерности их интеграции в процессе профессиогенеза? Вместе с тем подчеркнем, что рассмотренные материалы не только позволяют поставить эти значимые в теоретическом и практическом отношении вопросы, но и предоставляют необходимый эмпирический базис для их решения. 


\section{Ссылки}

1. Толочек В. А. Компетентностный подход и ПВК-подход: возможности и ограничения // Вестник СПбГУ. Серия 16: Психоло-гия. Педагогика. 2019. № 2. C. 123-137.

2. Chaiklin S., Sievert A. A theoretical model of nursing practice: Implications for a competence approach to nursing education // Nurse Education in Practice. 2019. № 36. P. 58-63.

3. Hojat M. Empathy in Patient Care: Antecedents, De-velopment, Measurement, and Outcomes By Mohammadreza Hojat. New York: Springer, 2007. 295 p.

4. Григорян Э. Г. Особенности внимания в професси-ональной деятельности специалистов медицинских учреждений // Изв. Сарат. ун-та Нов. сер. Сер. Акмеология образования. Психология развития. 2014. № 1. С. 91-97.

5. Кирдяшкина Т. А. Методы исследования внимания (Практикум по психологии): учебное пособие. Челябинск: Изд. ЮУрГУ, 1999. 72 с.

6. Шадриков В. Д. Проблемы системогенеза профес-сиональной деятельности. М.: Логос, 2007. 192 с.

7. ГОСТ Р 52623.3-2015. Технологии выполнения простых медицинских услуг. Манипуляции сестринского ухода: Нацио-нальный стандарт российской федерации: дата введения 2016-03-01. URL: http://docs.cntd.ru/document/1200119181 (дата обращения: 20.11.2020).

8. Инструкция по расчету стоимости медицинских услуг (временная) (утв. Минздравом РФ и Российской академией медицин-ских наук 10 ноября 1999 г. №№ 01-23/4-10, 01-02/41). URL: http://docs.cntd.ru/document/901839734 (дата обращения: 20.04.2021).

9. Nursing errors and their causes among nursing stu-dents / M. Mohsenpour [et al.] // Clinical Ethics. 2020. P. 1-7.

10. Nurses' communication skills and the quality of inpa-tient services from patients' viewpoints / A. M. Sharifabad Morowati [et al.]// Medical Science. 2019. 23(96). P. 163-167. URL: http://www.discoveryjournals.org/medicalscience/ current_issue/ v23/n96/ A5.pdf (дата обращения: 21.04.21).

11. The effects of teaching communication skills to nurs-ing students on the quality of care for patients / R. Taghizadeh [et al.] // Asian Journal of Pharmaceutics. 2018. 12. P. 1252-1255. URL: https:/www.researchgate.net/publication/332140294 _The_effects_of_teaching_communication_skills_to_nursing_students_on_the_ quality_of_care_for_patients (дата обращения: 11.04.2021).

12. Федеральный государственный образовательный стандарт среднего профессионального образования по специальности 34.02.01 Сестринское дело (утв. приказом Министерства образования и науки РФ от 12 мая 2014 г. N 502) URL: https://base.garant.ru/70683786/53f89421bbdaf741eb2d1ecc4ddb4c33/ (дата обращения: 11.04. 2021).

13. Hoeve ten Y. From student nurse to nurse professional: The shaping of professional identity in nursing: Dissertation. [Groningen]: Rijksuniversiteit Groningen, 2018. 212 p. URL: https://www.researchgate.net/publication/323773006 From_Student_Nurse_to_Nurse_Professional (дата обращения: 11.05. 2020). 
Жедунова Л. Г., Посысоев Н. Н.

14. Бабудоржиева Э. Д. Исследование проблемы ком-муникативных и организаторских способностей в психологии // Вестник БГУ. Образование. Личность. Общество. 2012. № 5. С. 41-45.

15. Stinson K. J. Benner's framework and clinical deci-sion-making in the critical care environment // Nurs Sci Quarterl. 2017. 30(1). P. 52-57.

16. Clinical decision-making in senior nursing students in Iran / F. Jahanpour [et al.] // International Journal of Nursing Practice. 2010. 16(6). P. 595-602.

17. Dicle A., Edeer Durmaz A. Examination of Clinical Decision Making Perceptions of Nursing Students // The New Educational Review. 2013. № 33. P. 134-144. URL: https://www.researchgate.net/publication/283264393_Examination_of_Clinical_ Decision_Making_Perceptions_of_Nursing_Students (дата обращения: 18.05.2021).

18. Карпов А. В. Метасистемная организация индиви-дуальных качеств личности. Ярославль: ЯрГУ, 2018. 744 с.

19. The Relationship between Nurses' Moral Sensitivity and Patients' Satisfaction with the Care Received in the Medical Wards / A. Elham [et al.] // Journal of Caring Sciences. 2019. 9. P. 98-103.

20. Williams J., Stickley T. Empathy and nurse education // Nurse Education Today. 2010. 30. P. 752-755.

21. Smith J. What is empathy for? // Synthese. 2015.194 (3). P. 709-722. DOI: 10.1007/s11229-015-0771-8.

22. Шадриков В. Д. Системогенез деятельности. Игра. Учение. Труд: монография: в 4 т. Т. I: Системогенез профессиональной и учебной деятельности. М.: Изд. дом РАО; Ярославль: ЯрГУ, 2017. 326 с.

23. Empathy with Patients Compared between First and Final Year Nursing Students / S. Saeidi [et al.] // J Holist Nurs Midwifery. 2017. 27(1): P. 79-85.

24. Sedaghati Kesbakhi M., Rohani C. Changes in the Level of Nursing Students' Empathy During Four Years Education // J Med Edu. 2020. 19(2). P. 100-179. URL: https://sites.kowsarpub.com/jme/articles/107179.html (дата обращения: 05.05.2021).

25. The Empathy Enigma: An Empirical Study of Decline in Empathy Among Undergraduate Nursing Students / J. War [et al.] // Journal of Professional Nursing. 2012. 28(1). P. 34-40.

26. Devi Aruna N. T., Eapen Annie A., Manickam L. S. S. A comparative crosssectional study on the level of empathy between the freshmen to senior undergraduate student nurses // International Journal of Advance Research and Development. 2020. Vol. 3, Issue 9, P. 10-15. URL: https:/www.ijarnd.com/manuscripts/v3i9/V3I9-1141. pdf (дата обращения: 18.05.2021).

27. Schramm Tobias J. T. Burnout am Arbeitsplatz von Krankenschwestern und Krankenpflegern in Bayern. Frankfurt/Oder, 2016. 440 p. URL: https://opus4.kobv.de/ opus4-euv/frontdoor/deliver/index/docId/214/file/Dissertation+Tobias+Schramm. pdf (дата обращения: 11.04. 2021).

28. Карпова Е. В., Коптева С. И. Формирование у бу-дущих педагогов эмпатии как профессионального качества // Ярославский педагогический вестник. 2019. № 2. C. $114-121$. 
29. Evaluation of nursing students' self-control in Turkey / A. O. Eyimaya [et al.] // J Pak Med Assoc. 2020.Vol. 70, No. 6. P. 1013-1017.

30. McCloughen, A., Levy, D., Johnson, A., Nguyen, H., McKenzie, H. Nursing students' socialisation to emotion management during early clinical placement experiences: A qualitative study. J Clin Nurs. 2020. P. 1-26. DOI: 10.1111/jocn.15270.

31. Пашукова Т. И., Допира А. И., Дьяконов Г. В. Прак-тикум по общей психологии для студентов педагогических вузов. М.: Институт практической психологии, 1996.177 с.

32. Ghasemi S., Ahmadi F., Kazemnejad A. Responsibility among bachelor degree nursing students: A concept analysis // Nursing Ethics. 2018, P. 1-12.

33. Ковылин В. С. Теоретические основы изучения фе-номена прокрастинации // Личность в меняющемся мире: здоровье, адапта-ция, развитие. 2013. № 2. C. $22-41$.

34. Khoshouei M. S. Prediction of procrastination consid-ering job characteristics and locus of control in nurses // Journal of Holistic Nursing and Midwifery. 2017. 27(2). P. 27-35. 